\title{
Towards a Team Approach to Understanding Board Effectiveness
}

\author{
Michael Wildenauer \\ Victoria University, Australia
}

\begin{abstract}
Research into board effectiveness has often been approached from a structural perspective and investigated using the financial performance of the organization, with limited success. However, boards are also elite teams and their effectiveness can this be studied in terms of group constructs. This paper provides a review of the literature which exists to support a team effectiveness approach to the effectiveness of boards, and exactly which parts of the team effectiveness literature are most suitable for behavioural research into board effectiveness.
\end{abstract}

\section{Keywords}

Board effectiveness, Board task performance, Board cohesiveness

\section{Introduction}

Boards are the ultimate governance organ of an organization, responsible for insuring that the organization adds value (however that may be defined) for shareholders (in the for-profit context) or some combination of shareholders and other stakeholders (in other organizational contexts). Understanding board performance in adding value, i.e. its effectiveness, is therefore important for stakeholders of all types (including directors, regulators and policy makers). The purpose of this paper

Copyright (C) 2015 Victoria University. This document has been published as part of the Journal of Law and Governance in both online and print formats. Educational and non-profit institutions are granted a non-exclusive licence to utilise this document in whole or in part for personal or classroom use without fee, provided that correct attribution and citation are made and this copyright statement is reproduced. Any other usage is prohibited without the express permission of the publisher. is to illustrate how board effectiveness can viewed through the lens of small group effectiveness; specifically as teams with interdependent tasks and cognitive outputs.

\section{Team Effectiveness}

Group effectiveness has been the subject of many studies in both the behavioural science and organizational literature over the years ${ }^{1}$.

\footnotetext{
${ }^{1}$ JR Hackman, 'The design of work teams' in J Lorsch (ed), Handbook of organizational behavior (Prentice Hall, 1987) ; Daniel J. Beal et al, 'Cohesion and Performance in Groups: A Meta-Analytic Clarification of Construct Relations' (2003) 88(6) Journal of Applied Psychology 989; Susan G. Cohen and Diane E. Bailey, 'What Makes Teams Work: Group Effectiveness Research from the Shop Floor to the Executive Suite' (1997) 23(3) (June 1, 1997) Journal of Management 239; Carsten K. W. De Dreu, 'Cooperative outcome interdependence, task reflexivity, and team effectiveness: A motivated information processing perspective' (2007) 92(3) Journal of Applied Psychology 628; Michael D. Ensley, Allison W. Pearson and Allen C. Amason, 'Understanding the dynamics of new venture top management teams: cohesion, conflict, and new venture performance' (2002) 17(4) Journal of Business Venturing 365; Luis L. Martins et al, 'A Contingency View of the Effects of Cognitive Diversity on Team Performance: The Moderating Roles of Team Psychological Safety and
} 
A team can be thought of as a specific type of group, and by one definition is defined as a group whose members have social interaction, some level of interdependency, a common goal or goals, and are part of a larger organizational context which influences their operation ${ }^{2}$. However the terms team and group are often used in a way which, while not exactly interchangeable, makes the actual object of analysis rather less clear. An example of this is "Group cohesion is one of the earliest and most widely studied team-process characteristics"3; with the example of "We use the words 'team' and 'group' interchangeably in this paper" ${ }^{4}$ at the extreme end of the scale. The terms 'work group' and 'team' do seem to be used more or less interchangeably in organizational behaviour and management literature however; for example the title of the paper "Enhancing the Effectiveness of Work Groups and Teams" ${ }^{\prime 5}$ seems to be the only place in it where these constructs are differentiated.

There are three dimensions of group or team effectiveness according to Cohen and Bailey ${ }^{6}$ : performance outcomes; attitudinal outcomes; and behavioural outcomes. The authors believe these outcomes to be a product of a combination of environmental context, group and task design, intra- and inter-group processes (e.g. conflict), and the psychosocial traits of the team (such as norms and cohesiveness). Other authors mention only the two dimensions of task performance and team satisfaction e.g. Shaw et al. ${ }^{7}$. These works, along with many others, employ adaptations of the InputProcess-Outcome (IPO) model first proposed by McGrath some 50 years ago ${ }^{8}$. Others such as Ilgen et al. ${ }^{9}$ have proposed an Input-Mediator-Outcome (IMO) model to account for the fact that some mediators between inputs and outcomes are not in fact processes, but for example, emergent states. This model was further developed by Ilgen et al. (the IMOI, or Input-Mediator-Outcome-Input model) to illustrate the episodic (execution of a set of processes at a particular time) or feedback-loop nature of team work. Mathieu et al. ${ }^{10}$ felt it necessary to point out that this feedback occurred in the transitions between episodes of teamwork, and not within them. Hackman ${ }^{11}$ on the other hand, proposed a normative rather than descriptive model, which specified the factors which should be present for group effectiveness. These factors were grouped into five broad categories: organizational context; group design; group synergy; process criteria of effectiveness and material resources. These

Relationship Conflict' (2013) 44(2) (April 1, 2013) Small Group Research 96; John Mathieu et al, 'Team Effectiveness 1997 2007: A Review of Recent Advancements and a Glimpse Into the Future' (2008) 34(3) (June 1, 2008) Journal of Management 410; Frances J. Milliken and David A. Vollrath, 'Strategic Decision-Making Tasks and Group Effectiveness: Insights from Theory and Research on Small Group Performance' (1991) 44(12) (December 1, 1991) Human Relations 1229; Jason D. Shaw et al, 'A contingency model of conflict and team effectiveness' (2011) 96(2) Journal of Applied Psychology 391; Ekaterina S. Bjørnåli, Truls Erikson and Mirjam Knockaert, 'The Impact of Top Management Team Characteristics and Board Strategic Involvement on Team Effectiveness in High-Tech Start-Ups' (2011) Academy of Management Annual Meeting Proceedings 1; Bongjin Kim, Mark Suazo and John Prescott, (2008) Exploring the Cognitive Nature of Boards of Directors and Its Implication for Board Effectiveness. College of Business, University of Texas at San Antonio, Working Papers: 0032; Karen A Jehn, Sonja Rispens and Sherry MB Thatcher, 'The effects of conflict asymmetry on work group and individual outcomes' (2010) 53(3) Academy of Management Journal 596

${ }^{2}$ Steve W. J. Kozlowski and Daniel R. Ilgen, 'Enhancing the Effectiveness of Work Groups and Teams' (2006) 7(3)

Psychological Science in the Public Interest 77

${ }^{3}$ Ibid, p87

${ }^{4}$ Cohen and Bailey, above 1

${ }^{5}$ Kozlowski and Ilgen, above 2

${ }^{6}$ Cohen and Bailey, above 1

${ }^{7}$ Shaw et al, above 1

${ }^{8}$ McGrath as cited in John Mathieu et al, above 1

${ }^{9}$ Daniel R Ilgen et al, 'Teams in Organizations: From Input-Process-Output Models to IMOI Models' (2005) 56(1) (02//)

Annual Review of Psychology 517

${ }^{10}$ Mathieu et al, above 1

${ }^{11}$ Hackman, above 1 
broad categories do however seem to correspond to the dimensions of effectiveness identified by other authors. In a review of research into the effectiveness of teams, Kozlowski and Ilgen ${ }^{12}$ listed a number of cognitive structures and processes (such as team mental models), interpersonal and affective processes and emergent states (for example cohesion), and team behavioural processes (e.g. team cooperation) which had found support in the literature as being related to team effectiveness. These authors criticized the IPO model as being rather dated and in need of extension, by virtue of its limited dynamic perspective of processes underpinning team effectiveness. In this they are in agreement with Hackman $^{13}$, who found the IPO model useful to organize thoughts, but less useful for understanding team effectiveness, as results were contingent upon the type of task being performed.

Mathieu et al. ${ }^{14}$ commented on the difficulty of neatly categorizing the constituents of team effectiveness, and the evolving complexity of these categories (ranging from the three outlined by Cohen and Bailey ${ }^{15}$, to more than twenty in some studies). For example, in a paper describing an extensive instrument developed to understand teams, Wageman, Hackman and Lehman ${ }^{16}$ developed criteria for an effective team based on earlier work by Hackman ${ }^{17}$ and others, which like Hackman's original model was normative. Their model did not identify causal or moderating factors for effectiveness, but rather viewed teams as evolutionary in nature which developed according to internal factors, and their interactions across external boundaries. Their criteria were as follows:

1. The output of team effort is viewed favourably by the recipient or user of that output according to the recipient's criteria (it is possible that teams may be the recipients of their own work)

2. Social processes used by the team enhance the ability to work well together in the future

3. Team members as individuals are positively affected by their team experience

Despite claiming not to specify causal factors, Wageman, Hackman \& Lehman hedged their bets somewhat by positing five conditions which enabled effectiveness, in their words "...when present increase the likelihood (but do not guarantee) that a team will perform well"18.

1. The team is not just a team in name only (it has member boundaries, is interdependent and working to a common purpose, and has some baseline level of membership stability)

2. The team's purpose is clear and compelling, with goals specified but the means of achieving them left up to the team

3. Team structure (task design, composition and shared conduct norms) enables cooperative work

4. The existence of organizational support for team tasks (rewards, learning and information)

5. The availability of coaching to minimize process loss and capture maximum process gains

\footnotetext{
${ }^{12}$ Kozlowski and Ilgen, above 2

${ }^{13}$ Ibid

${ }^{14}$ Mathieu et al, above 1

${ }^{15}$ Cohen and Bailey, above 1

${ }^{16}$ Ruth Wageman, J. Richard Hackman and Erin Lehman, 'Team Diagnostic Survey: Development of an Instrument' (2005)

41(4) (December 1, 2005) The Journal of Applied Behavioral Science 373

${ }^{17}$ Hackman, above 1

${ }^{18}$ Wageman, Hackman and Lehman, above 16
} 
As can be seen, a simple definition of team or group effectiveness is thus not easy to come by, and as Milliken and Vollrath ${ }^{19}$ pointed out, the types of group process and even the types of groups that will produce effectiveness is contingent to a large degree on which kind of tasks the group is to perform.

\section{Board Effectiveness}

It is a fairly uncontroversial fact that a board can be considered to be a team ${ }^{20}$, so a team effectiveness approach to board effectiveness would seem to be reasonable. Forbes \& Milliken proposed specific criteria suitable for the evaluation of boards as a specialized and specific type of team or workgroup ${ }^{21}$. The episodic nature of board functions; task complexity that involves the formulation and monitoring of strategy; the lack of implementation tasks; an almost wholly cognitive work output; and the fact that some or even the majority of team members had primary work affiliations with external organizations were given as evidence of this particularity. The authors asserted that the criteria of task performance and the board's cohesiveness (the continued ability to work together) were sufficient to determine board effectiveness ${ }^{22}$. This would seem to rescue those researchers studying board effectiveness from the untidy definitions of what constitutes team effectiveness detailed above. Lending weight to the inclusion of cohesiveness as an important component of board effectiveness was a meta-analytic study of cohesiveness and group performance which found that cohesiveness benefits performance especially when performance was defined as behaviour rather than outcome, and when the group's tasks involve the group working as a whole on them, e.g. decision making ${ }^{23}$. These group characteristics seem to fit boards well. Research findings linking cohesiveness with greater effectiveness in TMTs (top management teams) would also seem to support the inclusion of cohesiveness as a dimension of board effectiveness ${ }^{24}$.

Cornforth $^{25}$, in a study of non-profit boards (but where the research methodology was based on works in the corporate board domain) determined a set of five tasks that if performed effectively by the board best explained overall judgements of its effectiveness. These components were selected from a much larger set of board functions grouped into the areas of strategy making; stewardship; advising and overseeing management; board maintenance; and accountability, resource acquisition and networking. Cornforth also identified four process variables which he asserted helped explained variance in overall effectiveness: clarity in board role and responsibilities, shared vision with management of goal attainment, periodic reviews of board and management's working relationship, and ability to constructively resolve intra-board conflict. The lack of social interaction dimensions in this study of the effectiveness of what is essentially a very specialized team of people, and the inclusion of many tasks more suited to a more mature board environment may limit its ability to explain effectiveness

\footnotetext{
${ }^{19}$ Milliken and Vollrath, above 1

${ }^{20}$ Maarten Vandewaerde et al, 'The Board of Directors as a Team: Getting Inside the Black box' (2011) Proceedings of the European Conference on Management, Leadership \& Governance 435; G. Tyge Payne, George S. Benson and David L. Finegold, 'Corporate Board Attributes, Team Effectiveness and Financial Performance' (2009) 46(4) Journal of Management Studies 704

${ }^{21}$ Daniel P. Forbes and Frances J. Milliken, 'Cognition and Corporate Governance: Understanding Boards of Directors as Strategic Decision-Making Groups' (1999) 24(3) Academy of Management Review 489

${ }^{22}$ Ibid

${ }^{23}$ Beal et al, above 1

${ }^{24}$ Bjørnåli, Erikson and Knockaert, above 1

${ }^{25}$ Chris Cornforth, 'What Makes Boards Effective? An examination of the relationships between board inputs, structures, processes and effectiveness in non-profit organisations' (2001) 9(3) Corporate Governance: An International Review 217
} 
completely in a dynamic and informal startup board setting. In research which examined the perceptions of board members in New Zealand regarding the characteristics and outcomes they associated with effective boards, Northcott and $\mathrm{Smith}^{26}$ built on these results to construct a balanced scorecard for boards to measure board performance. This work is interesting both because it is grounded in a corporate environment analogous to Australia's, and because it acknowledges that 'softer' aspects of the board environment such as interpersonal dynamics and culture may be of more significance than structural elements in understanding the way that boards function. Directors in this study identified board relationships (both internal to the board and company and external to it) and board culture and practice as both inputs to, and outcomes of, board effectiveness. These directors also identified that both dimensions were of more importance than company performance as a measure of board effectiveness ${ }^{27}$.

Several aspects of the Northcott and Smith study would seem to diminish its use as a theoretical basis for future research however (while not affecting its practical utility in board evaluations). The first of these is that one of the authors is very much an insider as a director in New Zealand of long standing, which while allowing greater access to interview participants, may result in some biases of interpretation (likely not "enhancing the validity" as claimed ${ }^{28}$ ). Secondly the sample selection criteria may have resulted in a somewhat skewed set, with minimum tenure requirements for directors and minimum lifetimes for boards (though this last was explicitly stated as being required to reduce variability), which in an already small corporate environment may have excluded some valuable input. Finally the assertion that performance indicators for effectiveness are guided theoretically by either shareholder or stakeholder perspectives, ignored other worldviews (such as stewardship, political, and resource dependency approaches) and excluded other board functions such as the encouragement of desirable management behaviours, acquisition of resources, and the nurturing of innovation ${ }^{29}$.

In addition to their assertion that only two board level outcomes were important to understand effectiveness (task performance and cohesiveness), Forbes and Milliken ${ }^{30}$ identified three board processes which influenced these effectiveness dimensions; effort norms, cognitive conflict, and use of knowledge and skills. Effort norms included such things as devoting sufficient time to board 'homework' and attendance at meetings, in addition to levels of participation, attentiveness in meetings, and analysis of problems before them. Forbes and Milliken characterized cognitive conflict as enhancing the performance of board tasks but contributing via lowered levels of satisfaction to negative effects on cohesiveness. As this paper was written just as Jehn's important studies of intragroup conflict were beginning to be published ${ }^{31}$, the effects of a fuller range of conflict types which include task and relationship conflict did not appear to be considered by the authors. Later works have

\footnotetext{
${ }^{26}$ D. Northcott and J. Smith, 'Managing performance at the top: a balanced scorecard for boards of directors' (2011) 7(1)

Journal of Accounting \& Organizational Change 33

${ }^{27}$ Ibid

${ }^{28}$ Ibid, p 40

${ }^{29}$ Steven Murphy, A. and Michael McIntyre, L., 'Board of director performance: a group dynamics perspective' (2007) 7(2)

Corporate Governance: The International Journal of Effective Board Performance 209

${ }^{30}$ Forbes and Milliken, above 21

${ }^{31}$ Karen A. Jehn, 'A Multimethod Examination of the Benefits and Detriments of Intragroup Conflict' (1995) 40(2) Administrative Science Quarterly 256; Karen A. Jehn, 'A Qualitative Analysis of Conflict Types and Dimensions in Organizational Groups' (1997) 42(3) Administrative Science Quarterly 530
} 
shown these additional conflict types to be influential in Forbes and Milliken's effectiveness criteria ${ }^{32}$. These studies also emphasize the complexity of intra-group conflict processes and outcomes, which was perhaps not able to be accounted for in the Forbes and Milliken paper. Although these authors presented persuasive arguments in support of their useful restricted set of effectiveness criteria for boards, with the benefit of hindsight it would appear that the processes that they have identified as influencing these may be a necessary but insufficient set.

The integrated model presented in the Forbes and Milliken paper has since been employed by other authors such as Minichilli and Nielsen et al. ${ }^{33}$, and at least partially validated empirically by van Ees, van der Laan and Postma ${ }^{34}$ who found that process variables such effort norms, conflict and use of knowledge and skills influenced task performance in the monitoring and strategy board roles (although the authors found opposite polarities in the effects of cognitive conflict on these roles, perhaps due to limitations discussed above). A 2011 study which employed the Forbes and Milliken ${ }^{35}$ integrated model and also focussed on the antecedents of task performance, validated the positive effects of effort norms, use of knowledge, and cognitive conflict in a survey-based study of 119 listed company boards in the United States ${ }^{36}$. The cohesiveness component of the model on the other hand, seems to be little studied.

\section{Board Task Performance}

There are two main areas of focus in the board task performance literature, namely how to predict it, and how to measure it. It has been observed that various effects interacting in a dynamic fashion shape board task performance, and this complexity makes the isolation of predictors for it far from simple ${ }^{37}$. Huse $^{38}$ however, singled-out the decision-making culture of a board as the key predictor of task performance. This difficulty in identifying predictors of task performance may to some extent be due to the variation in task characteristics devolving from the various roles of the board, and the necessity for researchers not to treat these as an undifferentiated set in seeking to understand predictors for

\footnotetext{
32 Jehn, Karen A. and Elizabeth A. Mannix, 'The Dynamic Nature of Conflict: A Longitudinal Study of Intragroup Conflict and Group Performance' (2001) 44(2) The Academy of Management Journal 238; Jehn, Karen A. and Corinne Bendersky, 'Intragroup Conflict in Organizations: a Contingency Perspective on the Conflict-Outcome Relationship' (2003) 25(0) Research in Organizational Behavior 187; Jehn, Karen A et al, 'The Effects of Conflict Types, Dimensions, and Emergent States on Group Outcomes' (2008) 17(6) (2008/11/01) Group Decision and Negotiation 465; Jehn, Karen A. and Katerina Bezrukova, 'The faultline activation process and the effects of activated faultlines on coalition formation, conflict, and group outcomes' (2010) 112(1) (5//) Organizational Behavior and Human Decision Processes 24; Jehn et al (2010); Kerwin, Shannon, Alison Doherty and Alanna Harman, '“It's Not Conflict, It's Differences of Opinion”' (2011) 42(5) (October 1, 2011) Small Group Research 562; Shaw et al, above 1; Martins et al, above 1

${ }^{33}$ Alessandro Minichilli et al, 'Board task performance: An exploration of micro- and macro-level determinants of board effectiveness' (2012) 33(2) Journal of Organizational Behavior 193; Nielsen, Sabina et al, 'Board Diversity and Firm Performance: An Empirical Investigation of the Mediating Effects of Board Processes and Task Performance' (2008) Academy of Management Annual Meeting Proceedings 1

${ }^{34}$ Hans van Ees, Gerwin van der Laan and Theo J. B. M. Postma, 'Effective board behavior in The Netherlands' (2008) 26(2)

(4//) European Management Journal 84

${ }^{35}$ Forbes and Milliken, above 21

${ }^{36}$ Bernard C. Bailey and Simon I. Peck, 'Board Processes, Climate and the Impact on Board Task Performance' (2011) First International Conference on Engaged Management Scholarship, June 2011

${ }^{37}$ Pye, A. and A. Pettigrew, 'Studying board context, process and dynamics: Some challenges for the future' (2005) 16(SPEC. ISS.) British Journal of Management S27

${ }^{38}$ Huse, Morten, 'Accountability and Creating Accountability: a Framework for Exploring Behavioural Perspectives of Corporate Governance' (2005) 16 British Journal of Management S65
} 
them $^{39}$. Another difficulty is, given that performance criteria may be different for the same group for different tasks, and boards by their episodic nature ${ }^{40}$ tend to perform a number of these tasks in the one session, the overall task performance of the board for a particular episode may be difficult to predict or assess.

Several studies looking at board task performance have taken the approach suggested by the model proposed by Forbes and Milliken ${ }^{41}$; i.e. that the group-level processes of effort norms, task conflict, and use of skills and knowledge, all positively influenced task performance. One approach to the problem of assessing task performance is to evaluate various process criteria involved in the quality of strategies to perform tasks, effort, and use of skills and knowledge ${ }^{42}$. These map to the processes which influence task performance given by Forbes and Milliken ${ }^{43}$, though Wageman, Hackman \& Lehman omitted interpersonal criteria (such as the presence of, or quantum of, conflict) in the assessment of task performance (though did include them elsewhere in the instrument). Another, later, study took an approach that was more closely based on Forbes and Milliken's model, and asked CEOs to rate control performance and advisory task performance, and operationalized the concepts of effort norms (three items), cognitive conflict (four items based on Jehn's 1995 scale), and use of knowledge (three items). This study found support for effort norms and use of knowledge as predictors of both control and advisory task performance (positive), but a more confused picture with respect to cognitive conflict, which they suggested may be "context-specifically relevant" in a negative fashion ${ }^{44}$. This reflects the complexity perhaps inherent in seeking to ascertain magnitude and polarity of a highly contingent process using aggregation techniques.

The impact of various aspects of 'board climate' and board processes on the board control and service tasks, (with the Forbes and Milliken ${ }^{45}$ model as a starting point), was investigated by Bailey and $\mathrm{Peck}^{46}$, who found strong correlations between intra-group respect and a collaborative approach to board/TMT relations to effort norms and the use of knowledge and skills by the board, and the presence of cognitive conflict in decision making; all of which related positively to board task performance in control and service roles. Specifically, they found support for collaboration leading to positive effects in all of effort norms, cognitive conflict and use of skills and knowledge; and intragroup respect having a positive effect on effort norms and cognitive conflict.

Given the difficulties in understanding board task performance previously outlined, it would seem important to be able to identify the range of board tasks and their performance criteria, in order to gain an understanding of overall board task performance. Minichilli et al ${ }^{47}$ presented six tasks (three in each of the service and control roles, one in each role with each of internal, external and strategic foci), and scales for the evaluation of these. The authors gave these tasks as advice (service, internal), networking (service, external), strategic participation (service, strategic), behavioural control

\footnotetext{
${ }^{39}$ Alessandro Minichilli, Alessandro Zattoni and Fabio Zona, 'Making Boards Effective: An Empirical Examination of Board Task Performance' (2009) 20(1) British Journal of Management 55

${ }^{40}$ Forbes and Milliken, above 21

${ }^{41}$ Ibid

${ }^{42}$ Wageman et al, above 16

${ }^{43}$ Forbes and Milliken, above 21

${ }^{44}$ Minichilli et al, above 33, p 209

${ }^{45}$ Forbes and Milliken, above 21

${ }^{46}$ Bailey and Peck, above 36

${ }^{47}$ Minichilli, Zattoni and Zona, above 39
} 
(internal), output control (external) and strategic control (strategic). Other similar lists have been given in research on balanced scorecards for corporate boards in New Zealand (hiring and mentoring the CEO, directing and developing strategy, monitoring an compliance, adding value for and communications to shareholders, leadership around organizational culture, critical debate of issues, contribution of knowledge and skills), these being derived from the opinions of the directors themselves ${ }^{48}$; and board effectiveness in non-profits (17, divided up into the categories of strategy and policy making, stewardship, supervising and supporting management, board maintenance and external relations and accountability $)^{49}$.

In perhaps the most interesting approach, a list of tasks derived from board roles and used in coding transcriptions of actual board meetings was detailed in recent research by Machold and Farquhar ${ }^{50}$. These authors developed thirteen board tasks for their coding framework, allocated to one of five role categories (monitoring and control, service, strategy, dealing with external events, dealing with internal events). These last two categories are a deviation from most other categorizations, and were due to the observation that boards in reality spent considerable time on both being passive consumers of the dissemination of information, and in dealing with legal and compliance issues. This seems to correlate to anecdotal evidence from board practitioners that boards spend a lot of time 'ticking boxes' to comply with increasing levels of regulation and a lot of time listening to operational status reports.

Research studying the impact of shared leadership on board task performance has highlighted the impact of allowing those directors better able to lead the group at various times according to the subject at hand (e.g. directors who may be financial experts or IT experts) to do so. As this effect has been previously studied in other groups with cognitive outputs, where significant benefits have been shown, the authors have posited a similar effect on performance in control and service tasks for boards ${ }^{51}$.

\section{The Special Case of Early Stage Boards}

Interestingly, only two of the five tasks identified by Cornforth are among those discussed above as explicitly being part of the role of a startup board, namely resource acquisition and decision making around strategy. Another, overseeing financial management, is normally done in a more informal manner, and one, determining organizational culture, is implicit rather than explicit in nature. Reviewing board performance did not figure to any extent in the literature on startup board tasks. This would suggest that perhaps the performance of other tasks in Cornforth's ${ }^{52}$ set, such as provide advice to management, networking with external actors and representing stakeholders may be more useful in determining the overall effectiveness of the startup board.

Additionally, Forbes and Milliken ${ }^{53}$ recognized that boards of smaller firms (by the authors' classification, those with revenues of $\$ 25$ million or less) tend to perform a greater number of, and a

\footnotetext{
${ }^{48}$ Northcott and Smith, above 26

${ }^{49}$ Cornforth, above 25

${ }^{50}$ Silke Machold and Stuart Farquhar, 'Board Task Evolution: A Longitudinal Field Study in the UK' (2013) 21(2)

Corporate Governance: An International Review 147

${ }^{51}$ Maarten Vandewaerde et al, 'The Board of Directors as a Team: Investigating the Influence of Shared Leadership on

Board Task Performance' (2010) Proceedings of the European Conference on Management, Leadership \& Governance 365

${ }^{52}$ Cornforth, above 25

${ }^{53}$ Forbes and Milliken, above 21
} 
greater range of, service tasks due to the comparative lack of formality and lack of diversification. They also pointed out that because the senior management of small firms may be entrepreneurs lacking general management proficiency, the use of the board's knowledge and skills may assume a greater importance in board effectiveness in this case. High technology firms (both large and small) were also thought by Forbes and Milliken to be a special case, as directors needed knowledge and skills beyond those required for typical board service (i.e. technological and technology market knowledge), and typically had greater discretion in action because they possessed and could use this knowledge.

\section{Board Cohesiveness}

offered "a dynamic process which is reflected in the tendency for a group to stick together and remain united in the pursuit of its goals and objectives" ${ }^{24}$. At least one study has treated cohesiveness as an emergent state rather than a process, and posited that it has a positive effect on what they termed "group viability"; this latter was however defined in such a way to be fairly close to Carron's definition of cohesiveness above ${ }^{55}$. Much of the literature supports some sort of positive relationship between group cohesiveness and group performance ${ }^{56}$, even if the precise nature of that relationship has not been entirely clearly characterized. At least one study however, found that group cohesiveness was an antecedent of group performance, but the reverse relationship (which had been hypothesized by the authors) did not exist ${ }^{57}$. The absence of a causal relationship from group performance (self-rated) to cohesiveness was in direct opposition to early research (in a group of deep sea divers) where performance over time was found to engender cohesiveness, but not vice versa ${ }^{58}$. This may have been due to the fact that in this latter case team performance was taken to be mean total hours the team spent on task performance, or was an effect of observing cohesiveness during leisure time (only), or perhaps the fact that performance was a temporal antecedent to cohesiveness was inherent in the cohesiveness construct (some time is obviously required for a group to become cohesive ${ }^{59}$ ).

One approach to understanding the way that group cohesiveness may be measured is that of 'perceived' cohesiveness. In their paper, Bollen \& Hoyle ${ }^{60}$ chose to define cohesiveness as a combination of the sense of belonging to the group, and of feelings of morale; both as appraised by the individual. This research is interesting because it took a subjective approach to cohesiveness, rather than going down the objective path of observing and timing interactions as proxies of cohesiveness as did others (e.g. Bakeman and Helmreich ${ }^{61}$ ). However, their assertion that the cumulative effect of individual perceived cohesiveness could be used to characterize group cohesiveness stood on

\footnotetext{
${ }^{54}$ Albert V Carron, 'Cohesiveness in sport groups: Interpretations and considerations' (1982) 4(2) Journal of Sport

Psychology, p 124

${ }^{55}$ Jehn et al 2008, above 32

${ }^{56}$ Kozlowski and Ilgen, above 2

${ }^{57}$ Artemis Chang and Prashant Bordia, 'A Multidimensional Approach to the Group Cohesion-Group Performance Relationship' (2001) 32(4) (August 1, 2001) Small Group Research 379

${ }^{58}$ Roger Bakeman and Robert Helmreich, 'Cohesiveness and performance: Covariation and causality in an undersea environment' (1975) 11(5) Journal of Experimental Social Psychology 478

${ }^{59}$ Beal et al, above 1

${ }^{60}$ Kenneth A. Bollen and Rick H. Hoyle, 'Perceived Cohesion: A Conceptual and Empirical Examination' (1990) 69(2)

Social Forces (University of North Carolina Press) 479

${ }^{61}$ Bakeman and Helmreich, above 42
} 
somewhat shaky foundations on both theoretical (both Beal et al. and Kozlowski \& Ilgen $^{62}$ take issue with confounding individual with group levels of analysis), and practical grounds (an individual's perceived cohesiveness must remain invariant, and the total population of the group must be sampled).

It has been asserted that cohesiveness performs an important role in linking group outcomes with group processes, but that just how cohesiveness fits in, and the direction of causality, is unclear ${ }^{63}$. These authors posited that there are efficiency gains to be had by cohesive groups by way of greater motivation to complete tasks and because of a level of comfort between group members (which may lead to increased use of transactive memory, 'knowing who knows what' for example). For this reason they felt that investigating efficiency (where inputs were taken into account) rather than effectiveness outcomes (where inputs were not taken into account) would demonstrate stronger correlations between cohesiveness and performance. Their meta-analysis of 64 articles on the components of cohesiveness also found the correlation to be much greater where performance was defined as behaviours rather than outcomes of those behaviours (since these were likely to include exogenous factors ${ }^{64}$ ), and where the workflow of the group (task interdependence) was such that teamwork and collaboration was required $^{65}$.

Beal et al. ${ }^{66}$ also determined that three components of cohesiveness commonly used in research all had positive effects on performance, in ascending order of effect: interpersonal attraction, group pride and task commitment. Unfortunately results comparing these individual components of cohesiveness to behaviour/outcome, efficiency/effectiveness and workflow were not as conclusive due to sample size issues. Kozlowski and Ilgen's ${ }^{67}$ commentary on various meta-analyses restated Beal et al.'s position that many previous meta-analyses had confounded group-level and individual level effects and that under conditions of task interdependence, the relationship between cohesiveness and performance is stronger, and asserted that group cohesion is best understood as an emergent state, and is related to group performance in perhaps a reciprocal fashion.

Despite a number a research papers on cohesiveness being published in organizational literature (sufficient to conduct meta-analytic studies, e.g. Beal et al. ${ }^{68}$ ), very little which directly examines the components or dimensions of cohesiveness in boards of directors exists. In contrast to a number of studies in the psychological literature which have examined cohesiveness ${ }^{69}$, board literature has focussed largely on the effects of structural variables such as diversity (e.g. Erhardt, Werbel and Shrader ${ }^{70}$ ) and size (e.g. Muth and Donaldson ${ }^{71}$ ) on the social cohesiveness of the board. Even then, cohesiveness has typically been investigated either only as one of a number of precursors to financial

\footnotetext{
${ }^{62}$ Beal et al, above 1; Kozlowski \& Ilgen, above 2

${ }^{63}$ Beal et al, above 1

${ }^{64}$ Kozlowski and Ilgen, above 2

${ }^{65}$ Beal et al, above 1

${ }^{66}$ Ibid

${ }^{67}$ Kozlowski and Ilgen, above 2

${ }^{68}$ Beal et al, above 1

${ }^{69}$ Bakeman and Helmreich, above 42 ; Bollen and Hoyle, above 60; Rex Stockton, 'Developing cohesion in small groups: Theory and research' (1981) 6(4) (1981/11/01) The Journal for Specialists in Group Work 188; Albert A. Cota et al, 'The Structure of Group Cohesion' (1995) 21(6) (June 1, 1995) Personality and Social Psychology Bulletin 572

${ }^{70}$ Niclas L. Erhardt, James D. Werbel and Charles B. Shrader, 'Board of Director Diversity and Firm Financial Performance' (2003) 11(2) Corporate Governance: An International Review 102

${ }^{71}$ Melinda Muth and Lex Donaldson, 'Stewardship Theory and Board Structure: a contingency approach' (1998) 6(1)

Corporate Governance: An International Review 5
} 
performance of firms (or where firm performance has been used as a proxy for board performance), e.g. Dalton et al. ${ }^{72}$, or as a mediator between diversity and groupthink, rather than focussing on how cohesiveness per se is to be understood in the board context.

\section{Conclusion}

It can be seen that boards are elite teams, and as such board effectiveness may be understood in terms of team effectiveness. Forbes and Milliken ${ }^{73}$, supported by van Ees et al. ${ }^{74}$ and Bailey and Peck ${ }^{75}$ have shown that for this particular case of effectiveness, only the criteria of task performance and board cohesiveness need be considered, and have identified cognitive conflict, effort norms and the use of knowledge and skills as processes which influence task performance. Other conflict types and the cohesiveness criterion in general, have however been less studied and less well understood in the board context, and just which board tasks should be included and how contingent they might be in various organization types needs further study. Research to determine just how conflict and other group dynamics affect cohesiveness and task performance, and how these are manifested in real boards is also required.

\footnotetext{
72 Dan R Dalton et al, 'Number of directors and financial performance: A meta-analysis' (1999) 42(6) Academy of Management Journal 674

${ }^{73}$ Forbes and Milliken, above 21; Bailey and Peck, above 36; van Ees, van der Laan and Postma, above 34

${ }^{74}$ Van Ees, van der Laan and Postma, above 34

${ }^{75}$ Bailey and Peck, above 36
} 
